\title{
Participative Planning for Library Automation: The Role of the User Opinion Survey
}

\author{
Paul M. Anderson \\ and Ellen G. Miller
}

The University of Cincinnati Libraries adopted a participative planning philosophy in studying options to current manual record systems. Substantive, timely communications between user groups and library automation planners were considered vital to the design of a successful system. A major tool employed was an opinion survey sent by the University Libraries to 4,000 faculty, students, staff, and community users in the spring of 1981. The emphasis given by users to the public catalog broadened the planners' scope of system design from a circulationonly system to a public catalog/circulation system. The fact that library staff were surprised by some of the results underscores the necessity of involving the user in developing the system designed to meet their information needs.

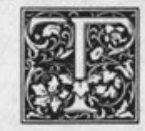

he two basic premises for planning library automation at the University of Cincinnati (UC) were to make the decisionmaking process as participative as possible and to involve existing groups and committees. We believed that these two premises would ensure a process that was as efficient as possible, while providing widespread dialogue among users, university administrators, and library staff. This philosophy was adopted for the following reasons.

First, the five UC library jurisdictions, which include Law, Medicine, two branch campuses, and the central university system, are among the university's most visible service units. Major changes the library jurisdictions contemplate are viewed with great interest and perhaps concern by user constituencies, especially faculty. Changes to library record systems, which link users with collections, must be undertaken carefully in an atmosphere of mutual concern and dialogue.
Second, university administrators respond more positively to proposed changes when planners from a service unit demonstrate that users have been part of the decision-making process. This has been recently demonstrated at the University of Missouri in its automation planning process. ${ }^{1}$

Third, the need for consulting the user in developing a successful information system is well documented in information science literature. Davis and Rush correctly argue that the user is the very reason for the existence of information systems. ${ }^{2}$ This can easily be overlooked in system modification and design. Today's librarian is faced with complex problems when designing an information system. Issues of bibliographic access, work-flow requirements, and the idiosyncrasies of computer hardware and software can be overwhelming. It is easy to lose sight of users or to consider their needs only after the system's needs, as defined by the librarian, have been met. The internal logic

Paul M. Anderson is head, Central Library Circulation Department, and Ellen G. Miller is director, Library Systems Development, both of the University of Cincinnati Libraries, Cincinnati, Ohio. 
or structure of the system can be emphasized at the expense of users.

Paisley and Parker suggest that the only proper criterion for evaluation of system success is user satisfaction, a criterion that is behavioral rather than structural. Although user satisfaction is difficult to measure through observing and interviewing users, it cannot be measured at all by studying only the system. ${ }^{3}$ Clearly, in the all-important matter of approach to the problem of system design, behavioral considerations must be preeminent. The first step in system design must be to consult the user. Consideration of the user must be a continuing, integral part of systems development. When user needs are known, the system can be shaped and adapted to meet them. Such an approach will minimize the adaptations required of the user to successfully use the system.

Fourth, widespread user participation would contribute to increased user understanding of key issues and facilitate users' ownership or support of the planning study's recommendations.

Fifth, it makes sense to use existing library and faculty groups, rather than to form new ones. Status information can be presented at regularly scheduled meetings. Volunteers can be sought from existing groups to help with specific tasks. Monthly progress reports can be distributed through formal organizational structures.

In summary, library automation planning was to be as widespread and undemanding as possible. Systems development was not to be thought of as the library's project, but rather as the university's project. The universitywide nature of the topic reflected the libraries' role as central to the instructional and research missions of the university. The threemember library automation team typified the universitywide scope of the planning effort: the director came from the Computing Center; the University and Medical Center libraries were represented by their head of circulation and assistant director of technical services, respectively.

Subsequent to adopting participative planning, two types of communicationone-way for status reporting and two-way for dialogue about issues-were identified. ${ }^{4}$ A strategy for their use was developed, focusing on a grid of key campus groups and persons, with appropriate methods for information or communication noted for each.

One method selected was the user opinion survey, a versatile tool that would permit two-way communication among large numbers of users, library staff, and automation planners. Its results would also become one-way feedback to the university at large. Reflecting different needs of the University and Medical Center libraries, two related but different survey instruments were developed. This article discusses the user opinion survey conducted by the University of Cincinnati Libraries.

\section{THE USER OPINION SURVEY}

Since the planning study's primary goal was to ensure that any new record system would meet future instructional and research needs, the survey looked closely at record systems directly affecting patrons to determine:

1. What needs were currently being met;

2. What improvements were needed;

3. What was the preferred sequence for automating record systems;

4. What special needs existed for particular user groups.

The resulting information would be used in the planning study's product, the Final Report. The purpose of the Final Report was to inform UC's vice-presidents about alternatives to manual library record systems and to make recommendations about future steps.

\section{Methodology}

A literature search was conducted to see if others had employed a user survey as part of the planning process for system design. Some of the survey instruments found in the literature search were of assistance in question design. ${ }^{6}$ However, none fit our objectives, and it was decided to develop our own survey instrument. A staff member working in the UC Medical Center Libraries, who had substantial experience in all phases of sampling methodology, questionnaire design, and analy- 
sis, temporarily joined the team. (For a brief bibliography on survey methodology and questionnaire design, see "Additional Sources."')

Theoretically the population for the survey were all potential users of the University of Cincinnati library system. For practical purposes the population was defined as faculty, students, staff, and known community users, a total of approximately fifty thousand people. Since the numbers of library staff and faculty were relatively small, and the active participation of both was considered essential to the design of an effective system, it was decided to survey a very large percentage of these groups. Accordingly, 100 percent of the library staff and full-time faculty and 50 percent of the part-time evening college faculty constituted the sample population.

The very large number of students, approximately thirty thousand, necessitated using much smaller samples. Differences in user opinions by college were of particular interest to the library. It seemed natural, therefore, to divide the students into twelve strata, one for each division (i.e., college). Due to great variance in the sizes of the student population among colleges and the assumed homogeneity within strata, different sample sizes were chosen for the various student strata. The formula used was $N=100+1 \%(P-N)$, where $N$ $=$ the number to be sampled and $P=$ the number of members in the strata. The strategy provides an opportunity for students from each college to return enough surveys to make analysis by college worthwhile. A straight percentage of each college's enrollment would have led to gross overrepresentation of the larger colleges. On the other hand, the fact that a percentage of enrollment is part of the formula gives fair representation to the colleges that constitute the bulk of the student body. A sampling size of 10 percent for the university staff and administrators and 25 percent for the community users was used. The percentages were arbitrarily chosen based on the rate of return expected for each group.

\section{Instrument Design}

Design of the questionnaire was the next step. It provided another opportunity for participative planning. The library automation team did not design the questionnaire but acted as the facilitator for an existing group, the Collections \& Information Services (CIS) selectors. This group of about twenty-three persons includes the subject bibliographers and the College \& Departmental library heads, all of whom are responsible for collection development and for liaison with faculty. It was felt that these individuals have the most contact with library users and, consequently, the best understanding of their use of the record systems.

The first contact with the CIS division was made at their regular weekly meeting. The purpose and objectives of the user study were put forth for approval or revision.

Photocopies of sample questionnaires from other university libraries were distributed to familiarize the group with various question formats. The group was asked to submit sample questions or mention areas that should be covered in the survey to members of the automation team.

The library automation team took these sample questions and developed a draft questionnaire, distributing it to participants prior to the next meeting. It took three more drafts and three more meetings to come up with a draft that could be presented to the library directors for final approval.

The next step was to pretest the questionnaire. Again, existing library groups were used. Faculty advisory committees participated as did several students. Only one question needed significant revision after the pretest.

A cover letter from the vice provost for University Libraries was distributed with all the questionnaires. This letter explained the importance of the project to the university and the importance of the user's responses in determining the course of future system design.

\section{Distribution}

The method of distributing the surveys varied for each user group. The surveys were distributed by the selectors to their 
respective faculty members. It was assumed that a professor of English literature, for example, would be more willing to respond to a survey given to him by his bibliographer than to a survey received in the mail. Using established collegial channels to ask faculty to evaluate present record systems was successful. For subject areas in which the ratio of librarians to faculty was high, the return was very nearly 50 percent. In areas where the ratio was low, the return was much lower.

The vice provost and his directors visited the president and vice-presidents, user opinion survey in hand. In most cases, the interviewee had other questions about the libraries and automation, permitting dialogue that otherwise rarely occurs between these two administrative levels. The interview helped establish name-face recognition, useful in later high-level briefings by the library managers about the Final Report's recommendations. Finally, the interview raised library automation's visibility among the people who would, in the end, allocate budgets. In practice, the interviews took about thirty minutes, although only fifteen minutes had been requested. This time overrun indicated interest by this crucially important administrative group.

The surveys were distributed through the mail to the rest of the user population. The method provided for the return of the survey can have great impact on the rate of return. Faculty, administrators and university staff, and library staff were asked to use the campus mail system, which is both convenient and free. Students were asked to drop the surveys off at the library. A healthy rate of return using this method was expected because the students are very heavy users of the library (exit figures at the Central Library alone exceed 1 million each year). In hindsight, this was a mistake. The method required too much of the student and the number of returned questionnaires fell below the number expected. Communication works best when the channels are most direct and convenient.

Community users holding library cards were surveyed after the mistake with the students had been discovered. In their case, a self-addressed business reply envelope was enclosed for the survey's return. There was no postage charge unless the envelope was mailed. In retrospect, this would have been the preferred method for the student surveys as well.

\section{Analysis}

The completed surveys were coded for machine processing and analyzed on the university mainframe computer via time sharing. The person who assisted with the methodology recommended using the Statistical Package for the Social Sciences (SPSS) for analysis of the data. ${ }^{7.8}$ The package is powerful and versatile, allowing a great deal of choice in which statistical operations are performed and how the data are presented, (e.g., tables, scattergrams, etc.). The package was used to derive frequencies for the various possible responses for each question. Crosstabulations comparing responses between questions were also run. Three graduate engineering students employed in the Central Library Circulation Department coded and keyed the data.

\section{Feedback}

As part of the commitment to ongoing communication, a meeting with the selectors was held when the survey results were ready. The library automation team hoped that librarians would consult the data in the printout so that the team would not be the sole interpreter of the results. Toward this end, some instruction was given on how to read the printout, especially the cross-tabulation tables. Next, the group was acquainted with the key findings. A handout of the questionnaire showing simple frequencies for each possible response for each question was distributed. Each librarian was given material that included cross-tabulations for their department or college. A complete copy of the seven-inch-thick printout was placed on reserve, along with a typed table of contents to facilitate browsing. It was stressed that all possible analyses had not been performed. Librarians interested in analysis not covered in the printout were encouraged to contact the team with suggestions. 
Two similar meetings were held to inform the library directors and the Access Division (i.e., technical services) department heads of the survey results and options for further analysis.

Articles about the survey's findings appeared in the library staff newsletter and in the campus faculty/administrator weekly newspaper. The planning study's monthly progress reports, sent out to more than 100 administrators, faculty, and library staff, regularly included the latest status on the user survey, its findings and conclusions. The user survey's findings greatly influenced the planning study's Final Report, which was also widely distributed.

\section{Rate of Return}

Of the 4,000 surveys distributed, more than 900 were returned. This was considered to be very good given the fact that the survey had been distributed late spring quarter, a particularly busy time of the year for faculty and students. A breakdown by user group appears in table 1 .

\section{Summary of Results}

The first question in the survey asked people how often they used the eleven campus libraries. Administrators and community users tended to concentrate their use on the Central Library. Faculty and students in subject areas with department libraries tended to split their use between those libraries and the Central Library.

The major surprise was the heavy faculty use. Of the nearly 40 percent of all faculty members who responded to the survey, 61 percent used the Central Library "two to three times per month or more" and 42 percent used it "once per week or more." Only 7 percent indicated never us- ing the Central Library, and nearly all of these indicated use of another library in the system.

The second question asked those surveyed to rank the reasons for using the library. As expected, the students identified their most frequent use of the library as "classroom related." The other four groups all rated "own research" as their most frequent use.

\section{Use of Current Record Systems}

Nine questions dealt with the present manual record systems. The results show that UC's patrons consider themselves successful in using these records.

The first question cluster focused on the periodical record system. A question was devoted to each of the separate files that constitute the system. Table 2 shows the results.

It had been anticipated that the periodical record system would receive low marks. The system is inconvenient. A patron frequently must consult all three files to get the information he needs. Only two of the files, the public catalog and the serial record, are located in close proximity to one another. Information from the Kardex can only be obtained by asking for assistance from a library employee. Information from the Kardex is only available Monday through Friday, 8 a.m. to 5 p.m.

It is probable that the helpfulness of the staff at the current periodical desk and the card catalog assistance desk is the key factor in the user's overall success with the system. The library instruction program's heavy emphasis on learning to find information in periodicals may also be important. Not surprisingly, community users, who do not participate in the library instruction program, had the least overall success in using the record system.

TABLE 1

RATE OF RETURN BY USER GROUP

\begin{tabular}{lrrr}
\hline User Group & Sample & Return & \% of Return \\
\hline Faculty & 1,109 & 436 & 39 \\
University administrator/staff & 500 & 122 & 25 \\
Library staff & 167 & 100 & 60 \\
Student & 2,048 & 218 & 11 \\
Community users & 250 & 36 & 14 \\
& 4,074 & 912 & \\
\hline
\end{tabular}


TABLE 2

SUCCESS WITH PERIODICAL RECORDS

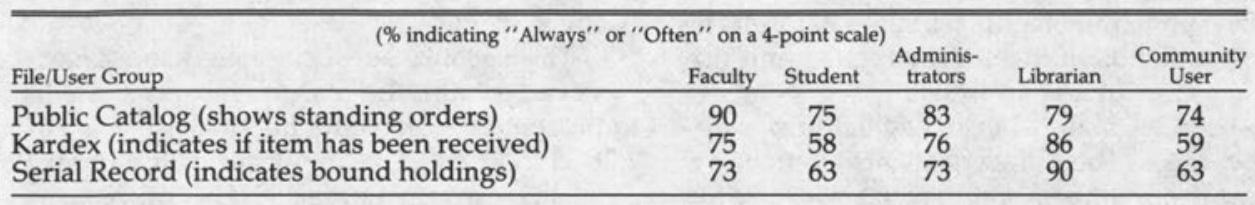

Three questions established that the user groups felt they were successful in using the public catalog (See table 3).

It is interesting that the lowest rating was given by the library staff. The public catalog at the Central Library is a 3,000drawer dictionary catalog. Like most longstanding card catalogs of this type, it has suffered from the many changes in cataloging rules. The low percentage of library staff who found the catalog easy or very easy to use may reflect this group's greater familiarity with the catalog's inconsistencies.

Two questions sought to determine how patrons felt about the convenience and accuracy of the present circulation record system. Patrons were asked to rate the present process of filling out transaction cards to borrow material. UC uses a notched-edge card system, which requires the patron to supply all borrower information (full name, address, phone number, and social security number) plus all book information (call number, author, and title) by writing it on a charge-out card. Forty-three percent of the students and 51 percent of the community users rated it poor or fair. Three-fourths of the faculty and university administrators/ staff, on the other hand, rated the system average or better. This higher rating no doubt reflects library policy that allows members of these two groups to give highly abbreviated patron information on the charge-out card, usually just last name and office number.

The question focusing on system accuracy asked the users how often they received overdue notices on items that they had already returned. Three to 6 percent of any group indicated that they often or very often received notices due to library error. This was much lower than librarians anticipated based on user comments received at the circulation desk. System accuracy should improve with automation.

\section{Sequence of Automating Record Systems}

A great deal of attention was given to the wording used for this question. First, automation was not assumed to be the only appropriate response in future system design. The question says, "If U.C. decides it can improve library service through automation, in which sequence would you like these improvements implemented?" Second, each of the three record systems, the public catalog, circulation records, and periodical records, was given a short explanation to ensure that the user understood exactly what he was rating. Third, the concept of the development of a totally integrated system was clearly implied. The user was not being asked whether he wanted an automated

TABLE 3

SUCCESS WITH THE PUBLIC CATALOG

\begin{tabular}{|c|c|c|c|c|c|}
\hline Question/User Group & Faculty & Student & $\begin{array}{c}\text { Adminis- } \\
\text { trators }\end{array}$ & Librarian & $\begin{array}{c}\text { Community } \\
\text { User }\end{array}$ \\
\hline $\begin{array}{l}\text { Rate use of the catalog (rated "easy" or "very easy" } \\
\text { on 5-point scale) }\end{array}$ & 71 & 61 & 59 & 40 & 69 \\
\hline "never" or "sometimes" on a 4-point scale) & 84 & 74 & 84 & 85 & 77 \\
\hline $\begin{array}{l}\text { Do you fail to find material due to incomplete } \\
\text { citations? (rated "never" or "sometimes" on a 4-point } \\
\text { scale) }\end{array}$ & 93 & 90 & 93 & 93 & 100 \\
\hline
\end{tabular}


catalog or an automated circulation system. He was being asked in which sequence he wanted these systems automated.

Response to the question among the major user groups was divided into two opinions. The faculty, university administrators/staff, and community users picked the public catalog as their choice to begin the automation sequence. Each of these groups rated circulation second. The students and library staff chose circulation first and rated the pur ic catalog second.

There was conside ible variety to the responses within s me groups. Table 4 shows the choice / faculty of various colleges to begin t? equence of automation.

There were cradivisional differences. Arts \& Scie. es naturally divides into three sections: humanities, social sciences, and sciences. Circulation was the first choice for the humanities and the social sciences. The sciences, however, chose the public catalog first and periodical records second. This is not surprising given the traditional emphasis periodical literature receives in the sciences.

\section{Open-Ended Suggestions}

The team felt that it was important to conclude the survey with an open-ended question. This type of question promotes two-way communication, by providing the user with the opportunity to write down whatever he deems important. He is not restricted to choosing among responses predetermined by the librarian.

By far the largest category of responses to this question concerned the size and quality of the collection. The next largest category concerned faster acquisition and cataloging of new material. It was apparent that some users did not fully appreciate the complexities involved in technical processing. Nevertheless, the message that a higher priority be given to reducing processing delays was clear. Other large categories dealt with College \& Departmental libraries and the circulation record system. Most wanted improvements in facilities for the former and a more convenient check-out procedure for the latter. Improvements in the physical environment, better access to periodicals, a more convenient way to place items on reserve, improvements in the order of books on the shelf, a reduction in the shelving backlog, longer library hours, and increased library instruction were also mentioned repeatedly.

\section{Other Concerns}

The remaining questions sought information on a wide range of topics thought to be pertinent to developing specifications for future system design. One question asked users to rate their most frequent point of access to the public catalog. For faculty and the library staff, the answer was overwhelmingly author. Com-

TABLE 4

CHOICE TO BEGIN SEQUENCE OF AUTOMATION by University of Cincinnati Divisions

\begin{tabular}{|c|c|c|c|c|c|c|}
\hline University Division & $\%$ & $\begin{array}{l}\text { talog } \\
\text { Frequency }\end{array}$ & $\%$ & $\begin{array}{l}\text { ation } \\
\text { Frequency }\end{array}$ & $\%$ & $\begin{array}{l}\text { Periodicals } \\
\text { Frequency }\end{array}$ \\
\hline Arts \& Sciences & 38.7 & 63 & 42.6 & 66 & 23.7 & 37 \\
\hline $\begin{array}{l}\text { College Conservatory } \\
\text { of Music }\end{array}$ & 50.0 & 11 & 52.2 & 12 & 5.0 & 1 \\
\hline $\begin{array}{l}\text { College of Business } \\
\text { Administration }\end{array}$ & 50.0 & 17 & 15.2 & 5 & 38.2 & 13 \\
\hline $\begin{array}{l}\text { Design, Art, Arch. } \\
\text { \& Planning }\end{array}$ & 76.2 & 16 & 30.0 & 6 & 16.7 & 3 \\
\hline Education & 31.7 & 13 & 32.6 & 14 & 39.5 & 15 \\
\hline Engineering & 51.2 & 22 & 35.0 & 14 & 26.7 & 12 \\
\hline Evening & 33.3 & 3 & 44.4 & 4 & 33.3 & 3 \\
\hline $\begin{array}{l}\text { Ohio College of } \\
\text { Applied Science }\end{array}$ & 62.5 & 5 & 0.0 & 0 & 37.5 & 3 \\
\hline University College & $\begin{array}{l}33.3 \\
43.4\end{array}$ & $\begin{array}{r}4 \\
158\end{array}$ & $\begin{array}{l}38.5 \\
36.6\end{array}$ & $\begin{array}{r}5 \\
130\end{array}$ & $\begin{array}{l}25.0 \\
27.0\end{array}$ & $\begin{array}{r}3 \\
94\end{array}$ \\
\hline
\end{tabular}


munity users, university administrators/ staff, and students indicated that subject was their first point of access.

There were some differences within user groups. A much higher percentage of the faculty of Arts \& Sciences, for example, chose author as the first point of access (74 percent) than did the faculty as a whole (57 percent). In sharp contrast were the faculty of the College of Business Administration and the College of Education. Sixty percent chose subject as their first choice. This may reflect fundamental differences in the way information is sought by these two colleges.

The issue of access to automated bibliographic records is complicated and can hardly be adequately addressed in one survey question. The high ranking given subject access by a majority of users, however, dictates that subject searching be given a high priority in the specification process. The fact that series was a seldomused point of access for all users may also have significance in defining priorities.

Another question sought to determine how much importance users placed on a good recall service. More than 70 percent of the students, community users, and university administrators/staff and more than 80 percent of the faculty and library staff rated a recall service as important or very important.

The purpose of another question was to determine the value users placed upon access to a union catalog at remote locations. The major user groups were enthusiastic about this possibility. Sixty-five percent of the faculty, 76 percent of the students, and 80 percent or more of the community users, university administrators/staff, and library staff rated remote access as valuable or very valuable.

Finally, users were asked if they had ever used a computerized library system. The purpose was to determine if our user groups were inexperienced in using automated systems and would, therefore, need a particularly cordial system. They were not. Approximately 25 percent of the students, community users, and university administrators/staff had experience in using such systems. The percentages were higher for faculty and library staff, 33 and 37 percent, respectively. The responses confirm that automated library systems are no longer uncommon.

\section{CONCLUSIONS}

Analysis of the surveys showed notable discrepancies between long-standing assumptions about user behavior in the university library system and the actual user perceptions. It had been anticipated that the bulk of the user population would indicate having problems with the manual record systems and that one or more systems would need immediate attention. This was not the case. Most of the respondents considered themselves successful in using these systems. Further, there was little difference among the effectiveness ratings of the three record systems. Since no record system is failing to meet user needs, the library can in good conscience spend the time required to give careful consideration to an integrated system. There is no need to hurriedly automate one function in order to compensate for record system failure.

Another surprise had to do with user perceptions of automation in the library. The users were expected to demonstrate considerable mistrust, even fear, of library automation. "Buy books not computers," was expected to be the resounding response to the open-ended question. It was not. There were many comments highly favorable to the idea of automation and only six to the contrary. There was, of course, concern over the future quality of the collection, but this was not to the exclusion of automated access to that collection. The user, it seems, wanted both a better collection and the greater convenience and access that could be offered by automation of library record systems.

Perhaps the most valuable information provided by the user was his preferred sequence of automating library record systems. This too proved to be something of a surprise. The library staff had, prior to the survey, chosen circulation as the most probable starting point for the automation sequence. The high rating received by the public catalog as the first choice of faculty, 
administrators, staff, and community users directly influenced automation planning.

These surprises underscore the importance of including a user survey in the planning process. Despite the close working relationship between many members of the library staff and the user, decisions based only on library staff perceptions would have inaccurately represented user perceptions and needs.

The Final Report cited the user survey's findings. For example, the first point made under "Recommendations" stated, "The first and second choices for automation (card catalog and circulation, respectively) and Medical Center's second choice (card catalog) can start to be satisfied by an online, decentralized record system for circulation control which also permits partial catalog search." Without the user survey's findings, the recommendations would have focused only on circulation control. In addition, an entire appendix was devoted to the user survey's purpose, distribution, return rate, and findings. Thus, top administrators had proof that faculty, students, and other user groups had been consulted and heeded. In an era of shrinking university budgets, a new project that must obtain funding will fare better when administrators can be assured that all user groups have had a hand in the recommendations. Without widespread participation, recommendations for automation could have been viewed as the library's pet project. The user study helped give the project universitywide legitimacy.

Whether involving the user very early in the planning process will succeed in developing his sense of ownership or commitment to the project remains to be seen. Certainly the survey heightened user awareness. The very good response rate to the survey suggests that the user is interested in the library system and willing to be involved in planning for its future. Whether user support and enthusiasm for library system's development can be maintained and nurtured depends upon two factors: first, the degree to which twoway communication between the user and library continues; second, the degree to which the resulting system meets the needs of the various user groups. While there are no guarantees that a participative planning process will lead to successful results, the probability of developing a system that meets user needs is certainly helped by involving the user in its planning.

\section{UPDATE}

As of spring 1983 the University of Cincinnati is moving rapidly toward its first goal, the acquisition of an online integrated public catalog/circulation system. Archival tapes of UC's holdings in OCLC have been sent to SOLINET, Inc., who will change the headings to comply with AACR2. Northwestern University's NOTIS software has been leased to edit the 350,000 machine-readable records upon their return from SOLINET. A dozen cataloging terminals, some of which will be available to the public, are on order for online data editing. A call for information to vendor and library organizations will be distributed in May 1983 and system selection is scheduled for late 1983. Participative planning has moved into a new phase with the establishment of several committees composed of library staff, faculty, and students. Committee responsibilities vary from drawing up functional specifications to designing and testing user educational assistance tools. The committee structure provides a new opportunity for user-librarian communication about library automation issues, options, and decisions. Communication is accomplished in several ways. Quarterly progress reports are sent to more than 100 university offices and individuals. Automation issues are brought before standing library, faculty, and administrative groups for discussion. Finally, draft documents prepared by the committees are reviewed by the heads of the five library jurisdictions. Given the economic difficulties facing the state of Ohio and its institutions of higher education, the role of the user opinion survey in justifying expenditure on this universitywide project by top administrators was very important. 


\section{REFERENCES}

1. James F. Corey, Helen H. Spalding, and Jeanmarie Lang Fraser, "Involving Faculty and Students in the Selection of a Catalog Alternative," The Journal of Academic Librarianship 8:328-33 (Jan. 1983).

2. Charles H. Davis and James E. Rush, Guide to Information Science (Westport, Conn.: Greenwood Pr., 1979), p.7.

3. William J. Paisley and Edwin B. Parker, "Information Retrieval as Receiver-Controlled Communication System," in Lawrence B. Heilprir, ed., Proceedings of the Symposium on Education for Information Science (Washington, D.C.: Spartan Books, 1964), p.26.

4. Anthony F. Grasha, Practical Applications of Psychology (Cambridge, Mass.: Winthrop Publishers, 1978).

5. Ellen G. Miller, "Strategic Roles of Communication and Information in Making Decisions to Automate Record Systems in One ARL Library," in 11th ASIS Mid-Year Meeting: Collected Papers, Knoxville, Tennessee, June 13-16, 1982 (American Society for Information Science).

6. Association of Research Libraries, Systems and Procedures Exchange Center, Office of Management Studies, User Statistics and Studies (SPEC kit, no.25 [Washington, D.C.: The Association, 1976]).

7. William R. Klecka, Norman H. Nie, and C. Hadlai Hull, SPSS Primer (New York: McGraw-Hill, 1975).

8. Norman H. Nie and others, SPSS: Statistical Package for the Social Sciences (2d ed.; New York: McGraw-Hill, 1975).

\section{ADDITIONAL SOURCES ON RESEARCH METHODOLOGY, QUESTIONNAIRE DESIGN, AND ANALYSIS}

General Research Texts:

Babbie, Earl R. The Practice of Social Research. Belmont, Calif.: Wadsworth Publishing Co., Inc., 1975. Miller, Delbert C. Handbook of Research Design and Social Measurement. 3d ed. New York: McKay, 1977.

Selltiz, Claire; Wrightsman, Lawrence S.; and Cook, Stuart W. Research Methods in Social Relations. 3d ed. New York: Holt, 1976.

Surveys and Questionnaires:

Berdie, Douglas R, and Anderson, John F. Questionnaires: Design and Use. Metuchen, N.J.: Scarecrow, 1974.

Oppenheim, Abraham N. Questionnaire Design and Attitude Measurement. New York: Basic Books, Inc., 1966.

Sampling, Statistics, and Data Analysis:

Mendenhall, William; Ott, Lyman; and Scheaffer, Richard L. Elementary Survey Sampling. Belmont, Calif.: Wadsworth Publishing Co., 1971. 